\title{
Empoderamento e atenção psicossocial: notas sobre uma associação de saúde mental ${ }^{*}$
}

Kamila Siqueira de Almeida ${ }^{1}$ Magda Dimenstein ${ }^{2}$ Ana Kalliny Severo 3

ALMEIDA, K.S.; DIMENSTEIN, M.; SEVERO, A.K. Empowerment and psychosocial care: notes on a mental health association. Interface - Comunic., Saude, Educ., v.14, n.34, p.577-89, jul./set. 2010.

Within the landscapes making up the Brazilian psychiatric reform movement, associative devices form a strategy for what can be called empowerment: boosting the strength and autonomy of users and their families involved in mental health. This paper had the aims of examining the functioning of an association bringing together users of mental health services, their families and professionals, and identifying the effects that it produces on the everyday lives of those who participate in it, along with the obstacles that clog their organization. Among these obstacles, we highlight the stiffening and bureaucratization of the association's functional routines and the predominance of participation and decision-making by technical experts. Accordingly, we see little participation and wielding of social control by users and their families, along with disconnection of the association from other local social movements.

Keywords: Health care reform. Mental health. Empowerment. Psychosocial care. Social control.
Nas paisagens que compõem o movimento da reforma psiquiátrica brasileira, os dispositivos associativos constituem uma estratégia para o que denominamos empoderamento: potencialização da força e da autonomia dos usuários e familiares envolvidos com a saúde mental. Este artigo objetiva analisar o funcionamento de uma associação que agrega usuários de serviços de saúde mental, familiares e profissionais e identificar os efeitos que produz no cotidiano daqueles que dela participam, bem como os obstáculos que entravam sua organização. Dentre esses obstáculos, destacamos o enrijecimento e a burocratização da rotina de funcionamento da associação e a predominância da participação e tomada de decisões por parte dos técnicos. Nesse sentido, percebemos pouca participação e exercício do controle social por parte dos usuários e familiares, bem como uma desarticulação da associação com outros movimentos sociais locais.

Palavras-chave: Reforma dos serviços de saúde. Saúde mental. Empoderamento. Atenção psicossocial. Controle social.
"Texto inédito, sem conflitos de interesse, elaborado com base em Severo (2009); pesquisa que recebeu financiamento do CNPq (bolsa de produtividade em pesquisa, mestrado $\mathrm{e}$ iniciação científica). 1 Graduanda em Psicologia, Universidade Federal do Rio Grande do Norte (UFRN). Bolsista de Iniciação Científica/ CNPq. Av. Afonso Pena, 520, Petrópolis, Natal, RN, Brasil. 59.020-100. kamilassiqueiras@ yahoo.com.br ${ }^{2}$ Departamento de Psicologia, UFRN. ${ }^{3}$ Curso de Psicologia da Universidade Potiguar, 


\section{Introdução}

Na Idade Moderna, a construção dos modos de subjetivação foi se ancorando na racionalidade e no sujeito de conhecimento, de forma a considerar desviante tudo o que diferia dessa premissa que ordenava o corpo social, tal como a loucura. O conceito de alienação mental nasce nesse contexto. Para a psiquiatria moderna, a alienação seria um distúrbio interior à própria razão e, portanto, passível de tratamento e cura pelo tratamento moral (Amarante, 1996). A condição para que este tratamento fosse profícuo era o isolamento do louco do seu meio social e a consequente reclusão aos muros do manicômio, justificada por uma maquinaria de poder-saber (Foucault, 2006a). Com a institucionalização do louco, segundo Foucault (2006b, p.262), o mesmo foi "privado de toda responsabilidade e de todo direito como membro da família, ele perdia inclusive sua cidadania, ele era fulminado pela interdição", de forma que os enunciados da psiquiatria edificassem um asilo ilimitado, disseminado pelo corpo social. Dá-se, então, um processo de tutelamento, no qual o saber técnicocientífico passou a legitimar leis que autorizavam regulações, interdições, dependência, com base na autoridade daquele que tratava (psiquiatra) e da proteção àquele que era destituído do poder de decisão (louco). Uma vez tendo comprometida sua razão, o louco torna-se inábil para gerir sua vida: essa responsabilidade teria de ser entregue a outrem, seja o Estado, seja o médico, seja o familiar. FoiIhe designado o silêncio e a incapacidade.

Os movimentos reformistas no campo da saúde mental, desde o fim da Segunda Guerra Mundial, vêm buscando interferir e transformar essa lógica, especialmente no que diz respeito ao empoderamento dos portadores de transtornos mentais e o incremento de seu poder de contratualidade na sociedade. As propostas de reabilitação psicossocial passam pelo exercício da autonomia e cidadania visando à inserção de pessoas secularmente estigmatizadas. Construir um novo lugar social para a loucura não deve restringir-se aos limites sanitários, mas estar atrelado à invenção de novos espaços e formas de sociabilidade e de participação (Dimenstein, Liberato, 2009). É nesse sentido que a concepção de empoderamento em saúde mental torna-se chave para a criação de autonomia e sociabilidade. O empoderamento aponta para

\footnotetext{
Uma perspectiva ativa de fortalecimento do poder, participação e organização dos usuários e familiares no próprio âmbito da produção de cuidado em saúde mental, em serviços formais e em dispositivos autônomos de cuidado e suporte, bem como em estratégias de defesa de direitos, de mudança da cultura relativa à doença e saúde mental difusa na sociedade civil, de exercício do controle social no sistema de saúde e de militância social. (Vasconcelos, 2008, p.60)
}

As concepções de empoderamento e participação social são linhas fundamentais na conformação do campo da saúde mental e coletiva. De acordo com Carvalho (2004a), tal categoria vem sendo incorporada às discussões voltadas ao ideário da promoção da saúde em diferentes perspectivas. Tal ideário - abordado pela Carta de Ottawa - inaugura uma vertente socioambiental da saúde, indicando serem necessários pré-requisitos como: justiça social, educação, saneamento, habitação, estabilidade do ecossistema e sustentabilidade dos recursos naturais. Efeito de uma série de fatores sociais, a ideia ampliada de saúde estende-se além do setor, e a intersetorialidade ganha valor crucial na construção de políticas públicas saudáveis (Carvalho, 2004b). Assim, a promoção da saúde ganha contornos de um processo de produção de sujeitos fortalecidos em suas capacidades de identificar e transformar os fatores que determinam a saúde.

Ao situar o empowerment no cerne das discussões do campo da saúde coletiva, o autor acima identifica dois sentidos para a categoria, um psicológico e outro comunitário, os quais implicam diferentes modos de conceber a produção de saúde, bem como em termos das intervenções, das práticas. O primeiro - associado a uma perspectiva behaviorista de promoção da saúde pela via da conscientização, aumento da autoestima e mudança de comportamentos não saudáveis - está focado no controle, pelos indivíduos, sobre a própria vida por meio de práticas educativas, traduzido pela máxima "cogito empowerment, ergo sum empowered" (Carvalho, 2004a, p.1091). É alvo de críticas 
${ }^{4}$ Para avançar nessa discussão, sugerimos a leitura de Carvalho e Gastaldo (2008) e Carvalho (2004b).

${ }^{5}$ Por Reforma Psiquiátrica concebemos um "movimento político, social e clínico no qual se forjam novas formas de lidar com a experimentação da loucura sem seqüestrá-la das cidades e da vida" (Fonseca, Perrone, Engelman, 2004, p.221). por endossar o discurso neoliberal de independência, responsabilidade pessoal e de afastamento do Estado na prestação de serviços sociais.

Quanto ao empowerment comunitário, não significa um rechaço ao desenvolvimento das capacidades dos sujeitos individuais preconizado na versão anterior. Porém, a tônica está na participação ativa nos processos decisórios, no fortalecimento dos modos coletivos de gestão, planejamento e decisão das políticas e ações em saúde. Trata-se de uma perspectiva mais integral na medida em que, segundo Carvalho (2004a, p.1092), demanda "a convivência da noção de determinismo social com a de agenciamento humano e o reconhecimento da mútua relação de condicionamento e determinação entre as macroestruturas e a ação de sujeitos individuais e coletivos". Nesse sentido, o autor considera central, nessa perspectiva, "a possibilidade de que indivíduos e coletivos venham a desenvolver competências para participar da vida em sociedade, o que inclui habilidades, mas também um pensamento reflexivo que qualifique a ação política" (Carvalho, 2004a, p.1092). Tal vertente de entendimento dos processos de empoderamento impacta de forma importante no contexto do SUS, fomentando discussões acerca dos saberes, tecnologias, práticas e discursos com os quais operamos cotidianamente, além de demandar mudanças de ordem institucional e subjetiva ${ }^{4}$.

Em sintonia com essa direção, especificamente no campo da saúde mental e na Estratégia da Atenção Psicossocial, a perspectiva da desinstitucionalização que as orienta implica a ampliação das estratégias de vida e de pertencimento de usuários para além do campo sanitário, bem como exige a diversificação dos espaços de socialização. O empoderamento é concebido não como transferência de responsabilidades ou mero usufruto de benefícios por usuários e familiares, mas como aumento da capacidade de eleição e ação: enxerga-os como coprodutores de políticas, por meio da corresponsabilização com diversos atores e do trabalho em rede entre diferentes instâncias sociais.

A ideia de empoderamento, portanto, é heterogênea e implica a criação de estratégias de potencialização da força e da autonomia dos usuários e familiares envolvidos com a saúde mental, dentre as quais os dispositivos associativos têm lugar de destaque (Vasconcelos, 2003). No Brasil, de acordo com a Coordenação Nacional de Saúde Mental (Brasil, 2005, p.39), “o processo da Reforma Psiquiátrica, e mesmo o processo de consolidação do SUS, somente é exeqüível a partir da participação ativa de trabalhadores, usuários e familiares na construção dos modos de tratar e nos fóruns de negociação e deliberação do SUS". Logo, trata-se de um protagonismo insubstituível.

As associações de usuários, familiares e trabalhadores em saúde mental vêm se constituindo como uma estratégia poderosa de participação política desses atores no cenário atual da reforma psiquiátrica e de luta antimanicomial. Porém, em tempos de uma Reforma Psiquiátrica ${ }^{5}$ já consolidada como política de Estado (pela Lei 10.216, de 2001), com pressupostos já manifestos nos discursos dos profissionais de saúde, dos familiares e dos usuários dos serviços de saúde mental, cabe analisar como essas associações vêm participando desse processo de luta complexo. Em outras palavras, queremos discutir de que forma vêm contribuindo para o rearranjo da malha institucional que vem sendo cerzida ao longo dos últimos anos; se conseguem agenciar novas maneiras de lidar com a diferença, novas relações entre a loucura e a sociedade e, por fim, questionar se ao louco ainda resta o silêncio e a inabilidade de outrora.

Este artigo pretende apresentar uma pesquisa realizada em uma associação de usuários, profissionais e "amigos" dos serviços de saúde mental situada em um município nordestino. Com base nos modos de atuação desse dispositivo 
e de como os usuários dos serviços de saúde mental se apropriam dele, acreditamos ser possível problematizar o campo dos movimentos sociais atrelados à Reforma Psiquiátrica. Adotamos, para tanto, o escopo conceitual da análise institucional (Lourau, 1993; Baremblitt, 1992) e de autores que abordam a questão da produção de subjetividade, grupos, e as novas configurações da luta política dos coletivos minoritários na contemporaneidade, tais como Foucault, Guattari, Rolnik, dentre outros. A escolha de um plano conceitual consiste, sobretudo, em uma aposta ético-política: tendo em vista a dissolução dos limites entre sujeito e objeto de pesquisa e da dicotomia entre teoria e prática, a intervenção é norteada pela implicação do pesquisador - o qual se utiliza dos conceitos para disparar processos de autoanálise e autogestão dos coletivos envolvidos, incluindo a si próprio.

\section{Breve histórico dos movimentos sociais em saúde mental no Brasil}

Os antecedentes das estratégias coletivas no âmbito da saúde mental remontam aos primeiros grupos de ajuda mútua, a saber, os Alcoólicos Anônimos, iniciados na década de 1930 e que, logo, foram disseminados geograficamente pelo Brasil (Vasconcelos, 2003). No entanto, várias críticas foram dirigidas a essas organizações pelos estudiosos dos movimentos sociais, sendo duas especiais: a ausência de preocupação em modificar as condições concretas de vida das pessoas que delas participam e a tendência de tais grupos a converter questões públicas em problemas privados ou de responsabilidade individual, tal como indicamos na vertente psicológica do empoderamento. Dessa forma, os grupos de ajuda mútua não estão tradicionalmente organizados de maneira a questionar e dar visibilidade às diferentes lógicas e contradições que os atravessam, e consequentemente, não focam em mobilizações que visem transformação social e o enfrentamento das raízes sociais dos problemas, convertendo-se em mantenedores da ordem social. Esse caráter deve-se a certos valores presentes na conformação dos grupos de ajuda mútua, tais como: seus elementos de inspiração religiosa, sua carga racionalista, o modelo médico em que estão ancorados, assim como a falta de abordagens sociais, políticas e culturais no seu modo de organização. Então, por que tais grupos foram considerados estratégias de empoderamento? Conforme Vasconcelos (2003), as principais contribuições desses grupos seriam sua estrutura descentralizada e a forma de organização nãohierarquizada, cujos encontros baseiam-se no processo de valorização da história de cada um para o enfrentamento dos problemas cotidianos.

O processo de engendramento da Reforma Psiquiátrica no Brasil, cujos primeiros relances se deram no final da década de 1970, teve estreita relação com os movimentos sociais que emergiam nesse período clamando por democratização. Mais precisamente na saúde mental, importavam-se cada vez mais as ideias e experiências vindas da Europa no que diz respeito ao questionamento dos paradigmas tradicionais da psiquiatria e na invenção de novas práticas contestadoras do manicômio. As primeiras mobilizações que ensaiavam a deflagração da Reforma brasileira tiveram, como ponto crucial, a formação do Movimento dos Trabalhadores em Saúde Mental (MTSM), ainda na década de 1970, o qual, num primeiro momento, reivindicava apenas mudanças genéricas da assistência psiquiátrica. O MTSM extrapola seu caráter sindicalista - de uma entidade composta por profissionais - alcançando o status de movimento social amplificado, por possuir propósitos orientados para a restituição da cidadania do louco escamoteada pela clausura e tutela, bem como para uma crítica ao saber e prática psiquiátricos e imagens sociais balizadas pelo paradigma racionalista (Amarante, 1996, 1995). Também, no final da década de 1970, ocorre a fundação da primeira associação de familiares de que se tem registro no Brasil, a Sociedade de Serviços Gerais para a Integração pelo Trabalho (SOSINTRA). Já a partir das décadas de 1980 e 1990, vê-se uma verdadeira proliferação de organizações, associações e grupos formados por usuários, familiares e profissionais dos recém-inaugurados sistemas de saúde mental substitutivos ao hospital psiquiátrico.

A partir de uma análise de tais movimentos sociais, percebe-se que as repercussões das transformações acionadas no campo de forças da saúde mental extrapolam questões acerca do modelo assistencial. Nos novos cenários modificados a partir da Reforma, as associações de usuários e familiares representam possibilidades de ação política orientada para uma maior visibilidade social (Souza, 2001), expressão dos interesses diretos dos usuários de serviços de saúde mental e seus 
"Por "instituinte" compreendo as forças que tendem a transformar (ou fundar) uma instituição. Por "instituição" refiro-me às "lógicas [...] que podem ser leis, podem ser normas e, quando não estão enunciadas de maneira manifesta, podem ser hábitos ou regularidades de comportamentos" (Baremblitt, 1992, p.25). familiares em vários sentidos: 1 Tentativa de mudança do estigma (Vasconcelos, 2008); 2 Possibilidade de transformação da clínica e de sua relação com os espaços sociais (Rodrigues, Brognoli, Spricigo, 2006); 3 Criação de táticas de controle social (Wendhausen, Barbosa, Borba, 2006); ou, ainda, de focos de resistência responsáveis pela produção de um devir-louco na sociedade (Guattari, Rolnik, 2005).

No mapeamento realizado por Vasconcelos (2009), nota-se que o perfil das associações em saúde mental no país caracteriza-se por serem associações mistas, criadas a partir de um Centro de Atenção Psicossocial (CAPS) ou ligadas a um, apoiadoras da reforma psiquiátrica e que cobram uma taxa financeira simbólica (dois a cinco reais). Por meio de tal investigação, transcorrida no período de 2004 a 2007, conseguiu-se contatar, ao todo, 107 grupos em todo o país. Desses, a maioria está concentrada nas regiões sudeste e sul - sendo 34 delas somente no estado de São Paulo - o que demonstra a concentração nessa região do país, bem como a pouca acessibilidade às associações sediadas nas regiões norte e nordeste. Lembramos que a amostra da pesquisa aqui referida remete à capacidade de contato com as associações, e não à quantidade de fato existente - capacidade essa relacionada à dificuldade de os próprios usuários e familiares locais realizarem o contato.

As maiores dificuldades enfrentadas por tais associações referem-se, sobretudo, às suas bases de sustentação econômica, política e institucional, mas também demonstram entraves para a comunicação e articulação com outros setores e correntes (Figueiró, 2009). Embora com décadas de história, a formação coletiva de usuários de serviços substitutivos e seus familiares ainda configura-se como um desafio no cenário político da saúde mental atual em que o saber técnico-científico da psiquiatria mantém sua hegemonia. Porém, essas formações proporcionam possibilidades de rupturas, ou seja, são capazes de produzir uma potência instituinte ${ }^{6}$ dentro de uma área marcada pela tutela e opressão, bem como dar voz a novos atores na Reforma Psiquiátrica: os usuários e seus familiares. Dessa forma, concordamos com o autor acima que

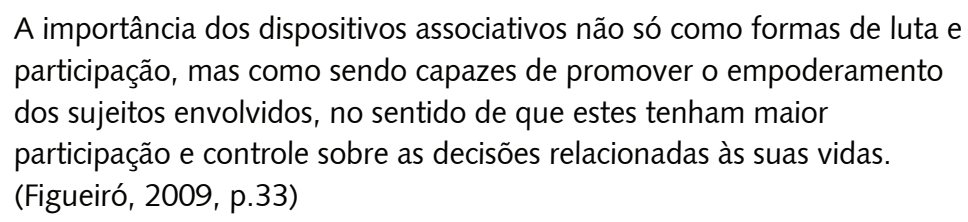

\section{Estratégias metodológicas}

Conforme Guattari, citado por Barros (2007), quando se pensa ou pesquisa um grupo, o que interessa é como ele opera, "o que ele dispara e faz fazer" (p.34). Nesse sentido, nos inserimos no campo de modo a investigar como uma determinada associação funciona, conhecer seus membros, e que efeitos ela produz na vida daqueles que dela participam. No município onde foi realizada a pesquisa existem duas associações de saúde mental: a associação $A$, de postura contrária à Reforma Psiquiátrica, e a associação $B$, braço da Associação Brasileira de Saúde Mental (ABRASME), a qual está dando seus primeiros passos, fazendo reuniões e mobilizações na cidade. Elegemos a associação $B$ para tal. Era nosso objetivo conhecer se a mesma contribuía para uma politização - no sentido de aumento de responsabilidade e autonomia - dos indivíduos que dela fazem parte, bem como investigar como a alta e os processos de reinserção social vêm sendo 
discutidos no interior da mesma. O trabalho de campo transcorreu durante três meses, entre novembro de 2008 e fevereiro de 2009.

Nessa associação participamos de duas reuniões da comissão de diretoria, uma roda de conversa com associados e uma reunião da associação junto à comissão pró-Associação Brasileira de Saúde Mental. A primeira das reuniões contou com quatro pessoas, sendo três integrantes da associação (dois desses usuários e um técnico); a segunda já contou com um usuário a mais, e a terceira contou com seis pessoas, sendo três, integrantes oficiais da associação - dois usuários e uma técnica. Em todos esses momentos, procuramos estabelecer um olhar cartográfico, uma vez que ele nos permite acompanhar os movimentos desenrolados durante o campo, a composição e transformações das paisagens psicossociais (Rolnik, 2007). Tal postura permite-nos, além disso, um olhar perspectivista sobre as diversas instituições que atravessam tanto os usuários e os membros da associação quanto nós mesmos. Dessa forma, implicamo-nos com aquilo que observamos, de modo a promover estados críticos no grupo, a fim de que um processo de análise fosse disparado, o que nos fez não só acompanhantes dos movimentos, mas impulsionadores deles (Mairesse, 2003).

Nesse trabalho de campo algumas dificuldades aconteceram, as quais foram tomadas como analisadores, pois muitas vezes propiciaram mudanças de estratégia de nossa parte, suscitandonos novas questões. Analisadores consistem em acontecimentos ou elementos, cuja materialidade expressiva é totalmente heterogênea (Baremblitt, 1992), capazes de suscitar a crise necessária para disparar um processo analítico, "que fazem aparecer, de um só golpe, a instituição 'invisível'" (Lourau, 1993, p.35). Um analisador pode ser uma palavra, um gesto, um acontecimento, um objeto, quaisquer dados que serviram para a análise a que estamos nos propomos. Dessa forma, alguns dos maiores empecilhos foram considerados como analisadores do estado em que a associação encontravase. A dificuldade de marcar reuniões e, quando marcadas, contavam com um reduzido número de pessoas, devido ao pouco contato dos diretores da associação entre si e com os usuários dos serviços substitutivos. A roda de conversa também contou com poucas pessoas e, por fim, não tivemos um bom substrato documental, pois a associada que estava de posse dos documentos oficiais esteve ausente em todos esses momentos.

\section{Os mo(vi)mentos da pesquisa}

Vasconcelos (2009), em sua pesquisa em nível nacional, categorizou as associações de acordo com os seguintes aspectos: a) modo de funcionamento, b) articulação com os serviços de saúde mental, c) tempo de existência, d) recursos (humanos, materiais e físicos) disponíveis, e) nível de formalização, f) formas de atuação dos membros, g) práticas e atividades desenvolvidas. Buscamos caracterizar a associação pesquisada segundo tais critérios.

A associação B é uma associação mista, fundada em 2005 a partir de um Centro de Atenção Psicossocial local; agrega usuários, familiares, profissionais e, ainda, a categoria "amigos" envolvidos com o sistema de saúde mental. Existe há cerca de quatro anos, mas somente oficialmente legalizada há dois, possui estatuto, mas não há contribuição financeira regular. Na primeira reunião de diretoria em que comparecemos, foram postos os seus objetivos e atividades desenvolvidas: englobar diversos aspectos da vida, tais como a esfera legislativa por meio da luta por direitos legais; a ação concreta a fim da assunção da cidadania; implementação de projetos que se destinem, dentre outras coisas, à capacitação dos usuários e a sua reinserção social; a conscientização da população, por meio da tentativa de mudanças nas representações sociais acerca da loucura; e a possibilidade de um espaço para amizades. Dentre as propostas está a tentativa de articulação entre os serviços, mas há uma focalização nos CAPS, talvez por ter sido formada a partir de um.

\section{Modos de atuação: enrijecimento e desarticulação}

Numa rua de difícil acesso no centro da cidade, encontra-se o Sindicato dos Trabalhadores Federais em Previdência, Saúde e Trabalho (SINDPREVS), local em que aconteciam as reuniões e assembléias da Associação no período em que a pesquisa foi realizada. Chega-se ao local e adentra-se em um 
auditório convencional com direito a cadeiras interligadas - para que não fossem desarranjadas - e mesa em cima de um pequeno palco à frente - para que os falantes estivessem em altura superior aos que ouvem. Na assembleia, havia pessoas que não conheciam a associação e nem entendiam do que se estava falando. Um rapaz levanta-se, toma a palavra e, ao falar de sua vida e questionar o que seria a Associação, causa um furo na pauta. Termina a reunião como começou. Auditório, palestra, pauta, desconhecimento. Que elementos são estes que compõem as reuniões da associação e que acabam por estagná-la? De que forma o modo de ação política está relacionado com a sua organização e com as instituições que a atravessam?

A roda de conversa que promovemos com alguns associados foi um marco na pesquisa, uma vez que promoveu um exercício de autoanálise (Baremblitt, 1992) entre aqueles que participaram. Dela fizeram parte quatro usuários - dentre os quais, três eram membros da comissão de diretoria, sendo um deles o presidente da associação - e uma técnica do ambulatório. Muitas das nossas impressões obtidas a partir de reuniões anteriores foram reiteradas pelos próprios participantes ali presentes. A iniciativa de promover uma discussão com certos usuários causou uma mobilização interessante. Nosso olhar ganha novo revestimento a partir de então, uma vez que, na conversa, os usuários apontam críticas à associação, bem como possibilidades de ação política.

Todos os usuários que participaram da conversa conheceram a associação por intermédio do serviço do qual fazem parte - um ponto que acreditamos ser positivo, devido à mobilização feita pelos técnicos para a divulgação. Eles apontam a associação, de maneira geral, como uma possibilidade de base de apoio para o usuário. Ela teria a função de promover ações que se destinam a uma reabilitação - cursos, oficinas e capacitações - que culminaria na desvinculação do usuário do serviço, uma vez que, segundo eles próprios, o usuário torna-se dependente do serviço porque fica ocioso e não tem outros suportes sociais.

Constatamos que uma das grandes demandas para os serviços substitutivos e para rede local que não dispõe de Centros de Convivência e Cultura é a questão do convívio e do estabelecimento de encontros. Além disso, foi possível notar que os usuários pouco sabem da dinâmica da rede de saúde para além do serviço que frequentam. Surge, então, a possibilidade de a associação ser um local de convivência, de interação, de troca de informações, de modo a configurar-se como um ambiente de sociabilidade e de produção de novas estratégias de vida. Dentre outros papéis atribuídos pelos usuários à associação estão: a conquista de direitos e melhor atendimento à saúde, medicação, lazer e benefício previdenciário, bem como um espaço de expressão e encontro. Tais expectativas expressas pelos usuários locais são corroboradas por outra pesquisa realizada por Rodrigues, Brognoli e Spricigo (2006), os quais investigaram as representações sociais dos integrantes de uma associação de usuários ligada a um CAPS do Rio de Janeiro. Nessa pesquisa, a associação é tomada como um espaço de informação e sociabilidade, lugar em que experiências podem ser compartilhadas, bem como de construção de autonomia e estratégia política para melhorias na assistência de saúde.

Observamos toda uma complexidade de fatores políticos, institucionais e financeiros que entravam a ação dos membros da associação pesquisada. No entanto, em uma roda de conversa, identificamos certas demandas que o modelo atual de associativismo não está atendendo, uma vez que passam pela luta por direitos civis, porém, não se restringem a esse âmbito. Trata-se de possibilidades de intervenção mais prementes, muitas vezes percebidas, mas não priorizadas por um olhar demasiado focado em questões voltadas à manutenção de uma ordem institucional e de representatividade. Questões que poderiam começar a ser atendidas com um simples passeio pelas vias públicas da cidade, por exemplo. São propostas da ordem de uma

Produção de formas de vida em sociedade - não um abandono da luta por financiamento, avanços técnicos, organizacionais, mas significa manter sempre vigilante nosso foco analítico em virtude da sedução fácil de determinados ganhos que aparentemente indicam a superação de modelos, mas apenas camuflam uma manutenção aprofundada de elementos fascistas que habitam em nós. (Alverga, Dimenstein, 2006, p.313) 
Na mesma roda de conversa, críticas feitas ao modo de atuação foram expressas pelos usuários. A falta de compreensão, dos usuários, de muitos assuntos tratados nas reuniões, assim como a distância desses temas, presentes nas assembleias, da realidade concreta, cotidiana, vivenciada por aqueles que frequentam os serviços de saúde mental. Outro ponto a ser destacado - e que acreditamos ser o nó górdio do então desempenho da organização - é o enrijecimento do modo de atuação, refletido pelo constante direcionamento das pautas para assuntos de cunho burocrático. Tal engessamento está relacionado a uma desarticulação entre os diretores da associação entre si e destes com os usuários. Estes alegam que pouco do que viram nas discussões das assembleias estava interligado com o cotidiano vivenciado dentro ou fora dos serviços. Ademais, uma das grandes dificuldades da associação está em reunir as pessoas, integrá-las. O número de participantes, em vez de crescer, vem diminuindo no decorrer das assembleias. Dentre os possíveis fatores apontados pelos usuários para essa pouca presença, estão desde a acomodação deles em manter seu percurso limitado entre casa e serviço, passando pela pouca informação que circula sobre a associação, até uma falta de interesse em virtude da formalidade característica das reuniões.

Dessa forma, notamos, na Associação, um processo de burocratização da mesma, isto é, um jogo entre a materialização das forças sociais em formas sociais padronizadas e normalizadas e as resistências a estas. A potência da associação está na criação de focos de resistência e novas formas de convivência. Focos que podem realizar desde transformações na escala das relações cotidianas e de circulação pela cidade, como podem ser apropriadas por setores inteiros das massas (Guattari, Rolnik, 2005), empreendendo estratégias de criação de novos espaços de convivência e cooperativas de trabalho, por exemplo. Focos que, no entanto, correm o risco de serem mortificados por uma agenda política burocrática e rigidamente formalizada. Destarte, o grande risco corrido pela associação é o enrijecimento da sua ação política e, não menos importante, de uma passividade dos usuários e familiares perante esse dispositivo, implicando um empoderamento ainda bastante tímido. No caso dos técnicos e dos seus dispositivos de ação, tendem a se institucionalizar e serializar, na direção da repetição e da imobilidade, o que, por vezes, acaba ocasionando a reprodução de uma subjetividade manicomial até mesmo em um espaço de problematização dela.

Diante da desarticulação, não só interna, mas com outros setores da sociedade, apontamos a necessidade de, tanto os serviços de saúde, quanto a associação estabelecerem conexões transversais e intersetoriais, a fim de que seja formada uma rede ampla e dinâmica, irrestrita às fronteiras da medicalização. Nesse sentido, nos é caro o conceito de transversalidade forjado por Guattari. Segundo o pensador e militante, o coeficiente de transversalidade designa a tendência de um grupo a realizar uma comunicação entre seus diferentes níveis e sentidos, bem como quão aberto é um grupo para estabelecer conexões com outros elementos e grupos, inclusive aqueles que lhe questionem. É justamente esse grau de abertura que dá a possibilidade de diferenciação ao grupo (Guattari, 1981). Como antídoto para esquemas rígidos e modelizados, apontamos, como necessária, a emulação de processos de tomada de responsabilidade individual e coletiva (Guattari, 1992), em outras palavras, uma gradativa intensificação do empoderamento por parte dos usuários. Mais precisamente, o incentivo à irrupção de processos instituintes no grupo. Com base no campo teórico-metodológico da análise institucional, apreendemos por jogo instituinte/instituído uma oscilação entre forças que tendem a se cristalizar por meio da hierarquização e reprodução de valores e sentidos hegemônicos, e forças que rompem com essa cristalização e reinventam sentidos e valores novos (Lourau, 2004, 1993; Baremblitt, 1992). É nesse movimento que a máquina institucional pode ser transformada: na contestação daquilo que impede a expressão do desejo e, portanto, de processos de ressingularização.

Uma proposta, já surgida na reunião seguinte à roda, foi a de criar uma nova forma de grupalização, que privilegiasse tanto essa aproximação diretoria-usuários, quanto os próprios usuários entre si, além de uma maior interação com a cidade. Uma das ideias que ocorreram foi a de se fazerem as "assembleias" - o termo agora aparece entre aspas porque ele próprio foi criticado por aqueles que estavam no encontro - no espaço urbano, em praças, por exemplo. Acreditamos que essa dinâmica articularia mais os associados, além de possibilitar uma mobilidade maior pela cidade, pressuposto básico para uma reabilitação efetiva (Basaglia, 1982 apud Torre, Amarante, 2001). 
Atualmente, observamos que a associação obedece mais a uma lógica totalizadora e identitária do que a uma lógica criadora que prima pela singularização daqueles que a compõem (Barros, 2007). Admitido e organizado sobre esse princípio, o grupo acaba por reificar uma suposta identidade coletiva, o que pode tornar-se uma ameaça à processualidade do movimento social (Guattari, Rolnik, 2005). Buscar uma identidade sacralizada, identidade em que o grupo pode acomodar-se, significa a circunscrição dos territórios existenciais - os quais remetem a uma multiplicidade - a um só sistema de referência e atribuição. No caso, a cruel identidade de doente mental, esquizofrênico, pirado, incapaz, enfim, uma série de atribuições que a loucura carrega. Daí emerge uma problemática que é, também, um dilema: como atuar no campo da luta por direitos compensatórios e políticas públicas sem assumir essa identidade? Tomá-la para si seria uma estratégia política para adquirir benefícios do Estado? Ou uma armadilha em que os movimentos de minorias estão sujeitos a cair?

\section{Os lugares do técnico e do usuário na dinâmica da Associação}

Embora haja presença de alguns usuários, percebemos que a liderança concentra-se nos técnicos e familiares. Neste ponto, é notável uma contradição quando os usuários alegam que são eles os que conhecem sua condição e sua realidade, mas, utilizando como subterfúgio a incapacidade historicamente atribuída à loucura -, acreditam que a associação precisa ser encabeçada por um técnico. Assim, enxergamos uma situação de passividade dos usuários frequentadores frente à associação. Entendemos que o fato de ser assistido por um serviço substitutivo ao hospital psiquiátrico e ter o discurso antimanicomial na ponta da língua não significa a derrocada absoluta de práticas e concepções demarcadas por um ranço asilar. Percebemos, nas falas dos usuários, um resquício da tutela a que foram historicamente delegados, como podemos perceber na seguinte fala:

"A gente tem transtorno mental, tem que ver que é uma doença. Porque hoje você está bem, amanhã você pode não estar, mas tem uma associação do lado. Eles [os técnicos] trabalham pra isso aí". (fala de usuária)

Vimos que, mesmo os usuários enfatizando que somente eles "sentiam na pele" a realidade nos serviços de saúde, acreditam que estão desabilitados para encabeçarem um grupo pela imprevisibilidade de uma crise e, por isso, os técnicos deveriam coordenar a associação. Por isso, são capturados pela noção de incapacidade, legitimada pela medicina e pelo direito, atribuída à loucura.

Vasconcelos $(2009,2008,2003)$ aponta que o perigo trazido pelo posicionamento de técnicos encabeçando os dispositivos associativos está no entrechoque de interesses entre estes, os usuários e os familiares, ocasionando uma assimetria de poder dentro da organização. Mas, o conflito de interesses, as relações de poder e as diferenças de perspectiva e expectativa não estão em nível interpessoal? Acreditamos, então, que depende de como os técnicos vão operar na associação de modo a favorecerem ou entravarem o processo de empoderamento dos usuários. Consideramos que os trabalhadores sociais

[...] se encontram numa encruzilhada política e micropolítica fundamental. Ou vão fazer o jogo dessa reprodução de modelos que não nos permitem criar saídas para os processos de singularização, ou, ao contrário, vão estar trabalhando para o funcionamento desses processos na medida de suas possibilidades e dos agenciamentos que consigam pôr para funcionar. (Guattari, Rolnik, 2005, p.37)

Estar à frente da associação torna-se, pois, uma questão de performance e tentativa contínua de dissolução dos blocos identitários (usuário-técnico-familiar-amigo): não mais de competência e/ ou lugar social. Trata-se de combater a tendência hierarquizante que permeia o grupo, onde tudo parece repercutir do topo para a base. Tanto os técnicos quanto os usuários precisam destituir-se das representações da loucura como incapacidade, inferioridade e doença mental, afirmando-a como 
diferença (Torre, Amarante, 2001). Ao tomar para si o poder de decisão - por mais que haja usuários no corpo diretório - e a incumbência de manejar a pauta, o técnico corrobora com a tutela, com a hierarquização das relações e, consequentemente, reforça a desarticulação da associação. Os usuários, por sua vez, destituindo-se da responsabilidade de cogerir a associação, reiteram e naturalizam o caráter de incapacidade atrelado à doença - reificando a identidade de doente mental, justificam a passividade perante as decisões do grupo.

Essas forças que atravessam os envolvidos acabam por paralisar a máquina institucional e ressonam em seu modelo de ação política. Conforme Torre e Amarante (2001, p.84):

A construção coletiva do protagonismo requer a saída da condição de usuário-objeto e a criação de formas concretas que produzam um usuário-ator, sujeito político. Isso vem ocorrendo através de inúmeras iniciativas de reinvenção da cidadania e empowerment [...].

Enxergamos, nas interpelações dos usuários durante a assembleia, uma força instituinte que coloca em xeque uma pauta dura, a qual estratifica a reunião. As críticas realizadas durante a roda de conversa refletem esse jogo de forças: por vezes, os usuários reclamam do "distanciamento da associação" para com a realidade vivenciada na saúde pública, bem como da extrema e mortificante formalidade das assembleias. Ao passo que são capturados pela infantilização ${ }^{7}$ e pela noção de incapacidade historicamente atribuída à loucura. Isentam-se da responsabilidade de reinventar a associação, delegando tal responsabilidade aos técnicos, uma vez que estes seriam competentes para estar à frente do grupo e lidar com a crise do outro. Um passo seria, pois, a desconstrução tanto do valor atribuído ao saber técnico, quanto da noção de incapacidade atrelada ao transtorno mental, presente no imaginário social e nos discursos dos usuários. O que não significa um rechaço ao profissional, posto que este deva ser impulsionador do empoderamento e da criação de novas formas de lidar com a loucura (Vasconcelos, 2003).

Os resultados do mapeamento já referenciado, realizado por Vasconcelos (2009), nos mostram que os problemas que aqui apontamos também ocorrem em uma escala nacional, isto é, as dificuldades analisadas não são exclusivas da associação local, mas estão presentes em grande parte dos dispositivos associativos do Brasil, sobretudo no que se refere à dependência aos profissionais e à articulação com outros movimentos. Primeiramente, ao tentar entrar em contato com associações, o autor percebeu que suas dificuldades em estabelecer esse contato já refletem problemas no acesso e na comunicação dos usuários e familiares com o próprio grupo. Além disso, os conflitos de forças presentes no campo da militância política e social podem promover um desvio de foco das formas de sociabilidade mais cotidianas, semelhante ao que acontece na associação em questão. Assim, esses problemas não estariam relacionados mais com a lógica que rege as redes de saúde mental - ainda uma lógica da infantilização e da tecnocracia - do que com a conjuntura específica de cada região? Seria essa lógica a responsável por entravar a criação e articulação de movimentos não-identitários e autonomistas?

Esses fatores abordados no transcorrer do trabalho contribuem para uma fragilidade da associação, enquanto processo político articulador de novas práticas, (Oliveira, Conciani, 2009) e um consequente enfraquecimento do controle social. Em termos de representatividade, a associação tem manifestado uma participação assídua (de alguns membros da diretoria) em fóruns de sindicatos e reuniões

\author{
Tal processo acontece \\ quando pensam e \\ organizam por nós a \\ produção e a vida social \\ (Guattari, Rolnik, 2005)
}


do Conselho Municipal de Saúde, sendo até convidada para tal, fato que demonstra um crescente reconhecimento por parte de outros setores da sociedade.

\section{Conclusão ou por uma pluralização da associação}

Viver é plural.

(Rosa, 1985, p.157)

Esta investigação evidenciou o enfraquecimento das tentativas de empoderamento dos usuários. Tal condição deve-se a uma complexidade de fatores institucionais, políticos e financeiros, e dentre os mais marcantes: o enrijecimento da rotina da associação, a passividade dos usuários e a liderança dos técnicos na gestão. Reuniões, assembleias e esquemas rígidos dificultam a circulação de informação dentro e fora da associação, bem como entravam um processo de mudança constante. Estabelecer contatos e alianças com outros movimentos sociais, organizações não-governamentais e projetos de ação social comporiam um solo profícuo para uma intervenção transversal do dispositivo associativo na vida daqueles que a compõem, na dinâmica da rede de serviços substitutivos ao manicômio e em outros setores da sociedade.

Movimentar-se para além das fronteiras sanitárias e para além e aquém da esfera da representatividade necessita de uma flexibilização da agenda política e uma inventividade cotidiana, a qual abrange desde os locais dos encontros à maneira com que eles são operados. Uma transversalidade torna possível compor um plano reticular de movimentos sociais, os quais, transformados em dispositivos geradores de desindividualização (Barros, 2007), formariam aquilo que Deleuze e Guattari (1995) chamaram de rizoma: não mais um eixo de onde partam grupos tomados como totalidades, mas linhas que se movimentam em múltiplas conexões.

Acreditamos que uma nova produção de cuidado e de vida pode se dar por meio do empoderamento daqueles que foram delegados ao silêncio e incapacidade, ou seja, uma militância política cujo pressuposto e objetivo são a autonomia e a intensificação da potência de vida e da possibilidade de decisão. E a criação propícia para que essa processualidade se mantenha passa fundamentalmente por um constante questionamento das instituições que nos atravessam e que nos fazem cristalizar modelos conservadores de lidar com a diferença. Atentamos também para a pertinência em enxergar o potencial terapêutico do empoderamento e da participação política, para a qual a associação é um dispositivo, com a formação de focos de resistência que podem ser expandidos no sentido da obtenção de direitos e criação de cidadania. Cidadania inventada não a partir da normatização, mas a partir da reabilitação, politização, onde o que está em jogo é a criação de novas subjetividades, um constante e re-atualizado processo do qual a singularização faz-se solo e ar: essa travessia que é libertar-se dos valores dominantes.

\section{Colaboradores}

Os autores trabalharam juntos em todas as etapas de produção do manuscrito.

\section{Referências}

ALVERGA, A.R.; DIMENSTEIN, M. A reforma psiquiátrica e os desafios na desinstitucionalização da loucura. Interface - Comunic., Saude, Educ., v.10, n.20, p.299-316, 2006. Disponível em: <http://www.scielo.br/pdf/icse/v10n20/03.pdf>. Acesso em: 21 maio 2009.

AMARANTE, P. O homem e a serpente: outras histórias para a loucura e a psiquiatria. Rio de Janeiro: Fiocruz, 1996.

(Org.). Loucos pela vida: a trajetória da reforma psiquiátrica no Brasil. Rio de Janeiro: Coleção Panorama/SDE/ENSP, 1995. 
BAREMBLITT, G. Compêndio de análise institucional e outras correntes: teoria e prática. Rio de Janeiro: Rosa dos Tempos, 1992.

BARROS, R. B. Grupo: a afirmação de um simulacro. Rio Grande do Sul: Ed. UFRGS, 2007.

BRASIL. Ministério da Saúde. Secretaria de Atenção à Saúde. DAPE. Coordenação Geral de Saúde Mental. Reforma psiquiátrica e política de saúde mental no Brasil. Documento apresentado à Conferência Regional de Reforma dos Serviços de Saúde Mental: 15 anos depois de Caracas. Brasília: OPAS, 2005.

CARVALHO, S.R. Os múltiplos sentidos da categoria "empowerment" no projeto de promoção à saúde. Cad. Saude Publica, v.20, n.4, p.1088-95, 2004a. Disponível em: <http://www.scielosp.org/pdf/csp/v20n4/24.pdf>. Acesso em: 21 abr. 2009.

As contradições da promoção à saúde em relação à produção de sujeitos $\mathrm{e}$ a mudança social. Cienc. Saude Colet., v.9, n.3, p.669-78, 2004b. Disponível em: <http://www.scielo.br/pdf/csc/v9n3/a13v09n3.pdf>. Acesso em: 30 ago. 2009.

CARVALHO, S.R.; GASTALDO, D. Promoção à saúde e empoderamento: uma reflexão a partir das perspectivas crítico-social pós-estruturalista. Cienc. Saude Colet., v.13, supl.2, p.2029-40, 2008. Disponível em: <http://www.scielosp.org/pdf/csc/v13s2/v13s2a07. pdf>. Acesso em: 20 abr. 2009.

DELEUZE, G.; GUATTARI, F. Rizoma. In: Rio de Janeiro: Editora 34, 1995. v.1. p. $\overline{11-37 .}$ Mil platôs: capitalismo e esquizofrenia.

DIMENSTEIN, M.; LIBERATO, M. Desinstitucionalizar é ultrapassar fronteiras sanitárias: o desafio da intersetorialidade e do trabalho em rede. Cad. Bras. Saude Mental, v.1, n.1, 2009. 1 cd-rom.

FIGUEIRÓ, R.A. Ajuda mútua entre usuários de CAPS: o papel do serviço no empoderamento dos usuários. 2009. Dissertação (Mestrado) - Programa de PósGraduação em Psicologia, Universidade Federal do Rio Grande do Norte, Natal. 2009.

FONSECA, T.M.G.; PERRONE, C.M.; ENGELMAN, S. Bárbaros no século XXI? What is barbarity in actuality? In: LINS, D.; PELBART, P.P. (Orgs.). Nietszche e Deleuze: bárbaros e civilizados. São Paulo: AnnaBlume, 2004. p.221-34.

FOUCAULT, M. O poder psiquiátrico. São Paulo: Martins Fontes, $2006 \mathrm{a}$.

A loucura e a sociedade. In: MOTTA, M.B. (Org.). Problematização do sujeito: psicologia, psiquiatria e psicanálise. Rio de Janeiro: Forense Universitária, 2006b. p.259-67. (Ditos \& Escritos, v.1).

GUATTARI, F. Caosmose: um novo paradigma estético. São Paulo: Editora 34, 1992.

Transversalidade. In: São Paulo: Brasiliense, 1981. p.88-105

GUATTARI, F.; ROLNIK, S. Micropolítica: cartografias do desejo. Rio de Janeiro: Vozes, 2005.

LOURAU, R. O instituinte e o instituído. In: ALTOÉ, S. (Org.). René Lourau: analista institucional em tempo integral. São Paulo: Hucitec, 2004. p.47-65.

Análise institucional e práticas de pesquisa. Rio de Janeiro: Universidade do $\overline{\text { Estado }}$ do Rio de Janeiro, 1993.

MAIRESSE, D. Cartografia: do método à arte de fazer pesquisa. In: FONSECA, T.M.G.; KIRST, P.G. (Orgs.). Cartografias e devires: a construção do presente. Porto Alegre: Ed. UFRGS, 2003. p.259-72.

OLIVEIRA, A.G.B.; CONCIANI, M.E. Participação social e reforma psiquiátrica: um estudo de caso. Cienc. Saude Colet., v.14, n.1, p.319-31, 2009. Disponível em: <http://www. scielo.br/pdf/csc/v14n1/a38v14n1.pdf>. Acesso em: 11 fev. 2009. 
RODRIGUES, J.; BROGNOLI, F.F.; SPRICIGO, J.S. Associação de usuários de um centro de atenção psicossocial: desvelando sua significação. Contexto Enferm., v.15, n.2, p.240-5, 2006. Disponível em: <http://www.scielo.br/pdf/tce/v15n2/a06v15n2.pdf>. Acesso em: 20 abr. 2009.

ROLNIK, S. Cartografia sentimental: transformações contemporâneas do desejo. Rio Grande do Sul: Ed. UFRGS, 2007.

ROSA, J.G. Tutaméia: terceiras estórias. 6.ed. Rio de Janeiro: Nova Fronteira, 1985.

SEVERO, A.K.S. Cronificação nos serviços substitutivos na rede de saúde mental de Natal/RN. 2009. Dissertação (Mestrado) - Programa de Pós-Graduação em Psicologia, Universidade Federal do Rio Grande do Norte, Natal. 2009.

SOUZA, W.S. Associações civis em saúde mental no Rio de Janeiro: democratizando os espaços sociais. Cad. Saude Publica, v.17, n.4, p.933-9, 2001. Disponível em: <http:// www.scielosp.org/pdf/csp/v17n4/5299.pdf>. Acesso em: 26 nov. 2008.

TORRE, E.H.G.; AMARANTE, P. Protagonismo e subjetividade: construção coletiva no campo da saúde mental. Cienc. Saude Colet., v.6, n.1, p.73-85, 2001. Disponível em: <http://www.scielosp.org/pdf/csc/v6n1/7026.pdf>. Acesso em: 28 nov. 2008.

VASCONCELOS, E.M. Perfil das organizações de usuários e familiares no Brasil, seus desafios e propostas. Cad. Bras. Saude Mental, v.1, n.1, 2009. 1 cd-rom.

(Org.). Abordagens psicossociais II: reforma psiquiátrica e saúde mental na ótica da cultura e das lutas populares. São Paulo: Hucitec, 2008.

O poder que brota da dor e da opressão: empowerment, sua história, teorias e estratégias. São Paulo: Paulus, 2003.

WENDHAUSEN, A.L.P.; BARBOSA, T.M.; BORBA, M.C. Empoderamento e recursos para a participação em conselhos gestores. Saude Soc., v.15, n.3, p.131-44, 2006. Disponível em: <http://www.scielo.br/pdf/sausoc/v15n3/11.pdf>. Acesso em: 20 abr. 2009.

ALMEIDA, K.S.; DIMENSTEIN, M.; SEVERO, A.K. Apoderamiento y atención psico-social: notas sobre una asociación de salud mental. Interface - Comunic., Saude, Educ., v.14, n.34, p.577-89, jul./set. 2010.

En los paisajes que componen el movimiento de la reforma psiquiátrica brasileña los dispositivos asociativos constituyen una estrategia para lo que denominamos apoderamiento: potenciación de la fuerza y de la autonomía de los usuarios y familiares involucrados a la salud mental. Este artículo tiene como objetivo el de analizar el funcionamiento de una asociación que incluye usuarios de servicios de salud mental, familiares y profesionales e identificar los efectos que produce en el cotidiano de quienes participan en ella, así como los obstáculos que entorpecen su organización. Entre tales obstáculos destacamos el enrigecimiento y la burocratización de la rutina de funcionamiento de la asociación y el predominio de la participación y toma de decisiones por parte de los técnicos. En este sentido percibimos poca participación y ejercicio del control social por parte de los usuarios y de los familiares, así como una desarticulación de la asociación con otros movimientos sociales locales.

Palabras clave: Reforma de la atención de salud. Salud mental. Apoderamiento. Atención psico-social. Control social. 
